\title{
GCU
}

Glasgow Caledonian

University

University for the Common Good

\section{Temporary suspension of visiting during norovirus outbreaks in NHS Boards and the independent care home sector in Scotland: a cross-sectional survey of practice}

Currie, K.; Curran, E.; Strachan, E.; Bunyan, D.; Price, L.

Published in:

Journal of Hospital Infection

DOI:

10.1016/j.jhin.2015.10.018

Publication date:

2016

Document Version

Author accepted manuscript

Link to publication in ResearchOnline

Citation for published version (Harvard):

Currie, K, Curran, E, Strachan, E, Bunyan, D \& Price, L 2016, 'Temporary suspension of visiting during norovirus outbreaks in NHS Boards and the independent care home sector in Scotland: a cross-sectional survey of practice: A cross-sectional survey of practice', Journal of Hospital Infection, vol. 92, no. 3, pp. 253-258.

https://doi.org/10.1016/j.jhin.2015.10.018

\section{General rights}

Copyright and moral rights for the publications made accessible in the public portal are retained by the authors and/or other copyright owners and it is a condition of accessing publications that users recognise and abide by the legal requirements associated with these rights.

Take down policy

If you believe that this document breaches copyright please view our takedown policy at https://edshare.gcu.ac.uk/id/eprint/5179 for details of how to contact us. 
The use of Temporary Suspension of Visiting during norovirus outbreaks in NHS Boards and the independent care home sector in Scotland; a cross-sectional survey of practice.

Running title: suspended visiting \& norovirus outbreaks

\section{Authors:}

Professor Kay Currie, Glasgow Caledonian University

Dr Evonne Curran, Health Protection Scotland

Ms Evelyn Strachan, Glasgow Caledonian University

Mr Donald Bunyan, Health Protection Scotland

Dr Lesley Price, Glasgow Caledonian University

\section{Correspondence to:}

Professor Kay Currie

School of Health \& Life Sciences

Glasgow Caledonian University

Cowcaddens Road

Glasgow G4 0BA

Email: k.currie@gcu.ac.uk

Phone 01413313472

Mobile 07877688578 


\section{Summary:}

\section{Background:}

Norovirus outbreaks cause significant patient distress and adversely affect healthcare service delivery. Measures to manage outbreaks include controlling patient/staff movement and advising visitors of the risks of infection; temporary suspension of visiting (TSV) is advocated by some. Factors influencing the use of TSV have not previously been reported.

Aim: To describe current practice in Scotland regarding TSV during norovirus outbreaks.

Methods: Cross-sectional survey of Scottish Health Boards (NHS) Infection Prevention Leads $(n=22)$ and Independent Care Home $[\mathrm{ICH}]$ managers $(n=107)$.

Results: TSV practice is inconsistent across care settings. NHS findings: although $86.4 \%$ reported a recent norovirus outbreak, only $36.4 \%$ reported having criteria in place to guide TSV decisions and only $57.9 \%$ of those who had an outbreak implemented TSV.

Conversely, $77.6 \% \mathrm{ICH}$ respondents do have TSV criteria in place; $70.1 \%$ who had previously experienced an outbreak all reported they would normally close to visitors. The majority of both NHS (81.8\%) and $\mathrm{ICH}(84.2 \%)$ respondents reported making exceptions to TSV for individual cases. Despite variation in practice, $75 \% \mathrm{NHS}$ and $81.8 \% \mathrm{ICH}$ respondents agreed TSV was helpful in controlling outbreaks. Factors influencing TSV implementation decisions included use of judgement in individual cases, perceived lack of evidence for the role of visitors in transmission, belief in patient's rights to have visitors.

Conclusions: Implementation of TSV in Scotland is inconsistent, with variation in the use of criteria, personal beliefs, and professional judgements evident. Further research on the role of visitors in transmission and service-user acceptability of TSV is required for policy development.

Key words: Norovirus outbreaks; suspended visiting; outbreak management 


\section{Background}

The effects of norovirus outbreaks in hospital wards and care homes can be significant, leading to additional patient care needs and increased staff sickness. In Scotland, noroviruses are the leading cause of healthcare related outbreaks and the commonest cause of healthcare service disruption due to ward closures. ${ }^{1 ; 2}$ Norovirus outbreaks peak during the winter months, challenging the NHS when the organization is at its busiest. ${ }^{3} \mathrm{~A} 3-$ year evaluation of the epidemiology and costs of noroviruses in one large Scottish Health Board identified expenditure in excess of $£ 1,000,000$ and a cumulative estimate of 3,678 bed days lost to these outbreaks. ${ }^{4}$ Most significantly, noroviruses present an increased risk of mortality for the frail and elderly. ${ }^{5}$

Public Health Advisors recommend that non-essential traffic within clinical areas be avoided during norovirus outbreaks, ${ }^{6}$ i.e. the ward should be closed to new admissions and transfers and that movement of staff should be significantly limited. Another commonly advocated means of reducing people 'traffic' in care areas is to restrict the frequency and number of visitors, with the complete temporarily suspension of all visitors (TSV) entering the affected area being advocated by some. Anecdotally however, there are concerns that preventing hospital patients and care home residents from having visitors may contravene their rights and is contrary to the ethos of person-centred care; therefore, it is not currently policy in the NHS in Scotland to impose TSV during norovirus outbreaks, although some areas may invoke this measure. Whilst the number of norovirus outbreaks in both the NHS and Independent Care Home $(\mathrm{ICH})$ sector is subject to national surveillance, we could find no reports on the extent of TSV use, or studies of the factors which influence TSV decisions in practice. The aim of our study was therefore to describe current practice in Scottish NHS Boards and $\mathrm{ICH}$ segarding temporary suspension of visiting during norovirus outbreaks.

\section{Research questions:}

- What proportion of NHS Boards / ICH respondents have criteria in place to guide TSV decisions?

- What criteria for TSV are used in practice?

- What is the relationship between the existence of criteria for TSV and actual implementation of TSV in NHS Boards/ICHs?

- What exceptions, if any, are permitted to TSV orders?

- What are respondents' views on the usefulness of TSV as a general control measure in outbreak managements? 
Confirmation was provided by the Regional Research Ethics Committee Coordinator that the proposed study met service evaluation criteria and did not require NHS Research Ethics approval; ethical review and approval was granted by Glasgow Caledonian University.

\section{Methods}

A cross sectional on-line survey was conducted via Surveymonkey®. Questionnaire items related to each of the research questions were developed in consultation with a clinical expert panel. A Likert scale format and open text boxes for additional comments were utilised. The tool was piloted with nursing colleagues for clarity and minimal changes to wording were made prior to use.

The survey was distributed via email link to a secure Surveymonkey® site to Infection Prevention \& Control (IPC) Leads in all 15 NHS Scotland territorial Health Boards and to independent care-home service managers via the 'Scottish Care' network (a national membership based organisation of Health and Social Care sector independent providers, which aims to promote partnership working to enhance and protect standards of care). Participants were provided with written information about the study, including an assurance of confidentiality, and completion of the survey was taken as consent to participate.

Data were entered into an excel spreadsheet and descriptive statistics (frequency counts and percentages) calculated. Content analysis ${ }^{7}$ was used to systematically describe and compare TSV practice across organizations.

\section{Results}

Respondents

IPC Leads from all 15 NHS Territorial Boards provided a response, with three larger boards providing more than one, reflecting their divisional structure $(n=22)$. The Scottish Care Network has a membership of approximately 400 ICHs; 107 care-home managers replied, giving an estimated response rate of $27 \%$. Participant codes are given in [brackets] after quotations.

\section{Norovirus outbreaks}

Nineteen (86.4\%) NHS respondents had experienced a norovirus outbreak in the previous two years, with just over half $(n=11,57.9 \%)$ reporting that TSV was applied. Seventy-five (70.1\%) ICHs reported having experienced an outbreak and all indicated they would normally apply TSV. 


\section{Use of criteria to guide TSV decisions}

Responses indicate inconsistent policy and practice nationally in relation to the availability and use of criteria to guide implementation of TSV: the majority of NHS Boards ( $n=14$, $63.6 \%)$ do not have TSV criteria in place; conversely the majority of ICHs ( $n=83,77.6 \%)$ do have TSV criteria available. The criteria used to guide TSV decisions reported by both NHS and ICH were largely dependent on the determination of an 'outbreak', with the number of cases required to meet this being variable (2-6 patients). Similarly, the decision to suspend visiting only to small bays with affected patients / residents, or the entire care area, varied across care settings: $73.3 \%(n=55)$ of ICHs who had experienced an outbreak closed their entire home; of the six NHS respondents who provided data, four closed the entire ward, two closed bays with affected individuals. Decisions regarding the extent of TSV within the care environment were partially determined by the layout and potential to restrict traffic within specific areas. However, professional judgement, rather than protocol, seemed to be the major operating principle in the NHS, as illustrated by the following comments

"It's [TSV] part of the escalation policy and would be assessed depending on the type of area and number of wards - it's not defined. The Outbreak Control Team would then decide when to return the visiting to normal." [NHS 11]

"Visiting would be suspended for any ward or hospital with persistent norovirus where it was believed that infection being brought in by visitors was a factor in maintaining the continuing outbreak" [NHS 19]

Less variability in decision making seemed to operate within the $\mathrm{ICH}$ sector, illustrated below:

"one case would lead us to close the unit where the case was, two or more would lead us to close the home, and we wouldn't re-open until we had three days clear of new cases" [ICH 48]

"First two cases of vomiting/diarrhoea within the home we would investigate norovirus. Close the home to visitors and keep visitors out until all possible cases are 48hr clear." [ICH 12]

Within the NHS, the relationship between the presence or absence of guiding criteria and the decision to implement TSV when an outbreak occurred was inconsistent. Nineteen (86.4\%) NHS respondents reported a norovirus outbreak in the last two years: eleven (57.9\%) of those implemented TSV although six (31.6\%) of these did not have TSV criteria in place which would have instructed this measure. Eight (42.1\%) NHS respondents did not 
implement TSV during an outbreak; however, two of these (10.5\%) had criteria which would have recommended this measure. Therefore, the availability of criteria and policy are not the only factor influencing TSV decisions in practice.

When asked to explain why TSV had not been implemented during an outbreak, seven of the eight NHS respondents for whom this was the case provided additional information, categorised as 'it was policy not to suspend visiting' ( $n=3)$; decisions were made 'on an individual basis'; 'the burden of symptomatic patients was not great enough to merit' (TSV)'; 'visitors were informed of the risk'; perceived lack of clarity of the evidence of the benefits of suspending visiting e.g.

"Unclear on the rationale for suspending visiting. Is it to protect visitors or the wards?" [NHS 24: this respondent indicated it was not their policy to use TSV]

"There was no evidence that infection being brought in by visitors was contributing to extending the duration of the closure [outbreak]" [NHS 19]

\section{Permitted exceptions to TSV}

Nine out of $11(81.8 \%)$ NHS Board respondents and 64 out of 76 (84.2\%) ICH respondents who had implemented TSV reported making exceptions by allowing visiting for individual cases in specific circumstances. These included when the patient/resident was terminally ill or palliative care was required ( $\mathrm{NHS} n=9 ; \mathrm{ICH} n=39$ ); when visitors have travelled a long distance to see patient/resident (NHS $n=5 ; \mathrm{ICH} n=10$ ); when the visitors insist on visiting (NHS $n=5$; ICH $n=10$ ); when the resident / patient is acutely ill ( $\mathrm{NHS} n=0 ; \mathrm{ICH} n=10$ ).

\section{Perceived usefulness of TSV as a general control measure in outbreak managements}

Despite inconsistencies in practice, the majority of respondents considered TSV to be a useful measure, with $15(75 \%)$ of NHS [2 missed responses] and $63(81.8 \%)$ of care-home respondents who had experienced outbreaks agreeing TSV was helpful in control management (Table I provides additional comments). 
Table I: Content analysis of views on ways which TSV helps outbreak management:

\begin{tabular}{|c|c|c|c|}
\hline Theme & $\begin{array}{l}\mathrm{NHS} \\
\mathrm{N}=21\end{array}$ & $\begin{array}{l}\mathrm{ICHs} \\
\mathrm{N}=54\end{array}$ & Illustration \\
\hline $\begin{array}{l}\text { Prevents } \\
\text { spread by } \\
\text { reducing } \\
\text { traffic }\end{array}$ & 4 & 31 & $\begin{array}{l}\text { "Less movement and general traffic seems to limit the spread" } \\
\text { [NHS 20] } \\
\text { "Helps to isolate and reduce risk of further spread." [ICH 53] }\end{array}$ \\
\hline $\begin{array}{l}\text { Prevents } \\
\text { spread } \\
\text { specifically } \\
\text { to or from } \\
\text { visitors }\end{array}$ & 4 & 18 & $\begin{array}{l}\text { "The public continue to visit when symptomatic or still shedding } \\
\text { thereby introducing the virus to healthcare" [NHS 11] } \\
\text { "Several outbreaks have been linked to visitors + some visitors } \\
\text { may have added to the bioburden of the outbreak area" [NHS 13] } \\
\text { Care-homes: } \\
\text { "We close the home mainly for the protection of visitors to the } \\
\text { home." [ICH } 35 \text { ] } \\
\text { "Relatives may get the virus and then reintroduce it to the home." } \\
\text { [ICH 18] } \\
\text { As opposed to } \\
\text { "Asymptomatic visitors do not present a risk to the ward." [NHS } \\
23 \text { ] }\end{array}$ \\
\hline $\begin{array}{l}\text { More nursing } \\
\text { time for } \\
\text { patient care }\end{array}$ & 3 & 8 & $\begin{array}{l}\text { "Helps to focus nursing care on the patients during what is } \\
\text { normally a very busy time." [NHS 10] } \\
\text { Care-homes: } \\
\text { "Enables staff to focus more on residents affected." [ICH 14] } \\
\text { "Dignity of resident, staff able to concentrate fully on residents } \\
\text { care." [ICH 33] }\end{array}$ \\
\hline $\begin{array}{l}\text { Increases } \\
\text { awareness } \\
\text { of infection } \\
\text { control } \\
\text { processes }\end{array}$ & 0 & 3 & $\begin{array}{l}\text { Care-homes: } \\
\text { "Raises awareness of good hand hygiene etc" [ICH 15] } \\
\text { "Controlled use of personal protective equipment for all." [ICH 17] }\end{array}$ \\
\hline $\begin{array}{l}\text { Contrary to } \\
\text { patients' } \\
\text { rights }\end{array}$ & 1 & 0 & $\begin{array}{l}\text { "Directly conflicts with moves towards 'open visiting' ... Long stay } \\
\text { patients may not benefit from social interaction/contact for } \\
\text { (perhaps) a lengthy spell". [NHS 3] }\end{array}$ \\
\hline $\begin{array}{l}\text { Lack of } \\
\text { evidence }\end{array}$ & 2 & 0 & $\begin{array}{l}\text { "Not sure how robust the strategy is" [NHS 10] } \\
\text { "Not sure as we have never fully stopped visiting" [NHS 17] }\end{array}$ \\
\hline
\end{tabular}

All respondents were offered the opportunity to make any other comments about TSV; 12 NHS and 29 care-home respondents answered (Table II). Categorisation of responses indicated the majority of respondents identify the potential value of TSV in containing outbreaks. However, whilst some respondents suggested that TSV was 'nothing new' and routinely practised, others commented that it was not a standard strategy, whilst others acknowledged the need for national policy. Visitors' perspectives were also highlighted, with most comments suggesting visitors were usually understanding once informed, although one NHS respondent said the measure was not well received by Public Partners to the NHS Board; that particular Board does not generally implement TSV, but advises visitors of potential risks. Additional points raised by $\mathrm{ICH}$ respondents included the need for greater 
education and awareness-raising of norovirus and suspended visiting for the public; the potential negative impact of extended TSV on residents; the challenges of managing staff movement and one respondent noted the financial implications of closing the home to new admissions during norovirus outbreaks.

Table II: Additional comments on the use of TSV (N.B. some respondents provided comments in more than one category)

\begin{tabular}{|c|c|c|c|}
\hline Theme & NHS & $\mathrm{ICH}$ & Illustrative comment \\
\hline Containment & 5 & 8 & $\begin{array}{l}\text { "I think it is a good measure to put in place when measures normally } \\
\text { used for controlling an outbreak are not sufficient to control it." [NHS } 6 \text { ] } \\
\text { "It is Ok so long as the outbreak doesn't last too long. Communication } \\
\text { with regular updates is vital." [NHS 20] } \\
\text { "I think it is imperative to close the home as the virus can be } \\
\text { contained..." [ICH 9] } \\
\text { "It makes sense to reduce the potential for spread of infection." [ICH 15] }\end{array}$ \\
\hline $\begin{array}{l}\text { Lack of clarity Vs } \\
\text { routine policy }\end{array}$ & 5 & 2 & $\begin{array}{l}\text { "This is not new! This has been recommended + practiced for many } \\
\text { years" [NHS 13] } \\
\text { "If there was a National Policy, this would support our adoption of visitor } \\
\text { suspension at such times. We would be in favour of this." [NHS 3] } \\
\text { "It is something that requires risk assessment based on the burden in } \\
\text { the ward staff affected etc at the time and we would not routinely } \\
\text { suspend visiting" [NHS 17] } \\
\text { "Although we did close to visitors temporarily we were advised by the } \\
\text { public health nurse that this was not necessary. We therefore re-opened } \\
\text { to visitors" [ICH 27] }\end{array}$ \\
\hline $\begin{array}{l}\text { Visitors } \\
\text { perspectives }\end{array}$ & 2 & 5 & $\begin{array}{l}\text { "I feel that visitors are usually very understanding if the ward is closed to } \\
\text { visitors providing that this is fully explained to them" [NHS 5] } \\
\text { "We discussed this with our Public Partners around } 2012 \text { \& also raised it } \\
\text { as a query on our public website. Although small in number it was not } \\
\text { received well" [NHS 18] } \\
\text { "Most visitors were understanding and happy to comply" [ICH 19] }\end{array}$ \\
\hline $\begin{array}{l}\text { Raising } \\
\text { Awareness/ } \\
\text { Education }\end{array}$ & 0 & 8 & $\begin{array}{l}\text { "It would be good if awareness levels of the Norovirus could be raised } \\
\text { with the public at large" [ICH 10] }\end{array}$ \\
\hline $\begin{array}{l}\text { Impact on } \\
\text { residents and } \\
\text { relatives }\end{array}$ & 0 & 6 & $\begin{array}{l}\text { "It can be very unsettling for residents and relatives...especially when it } \\
\text { goes on for an extended period" [ICH 13] }\end{array}$ \\
\hline Staff movement & 0 & 2 & "Staff entering and leaving environment can be an issue" [ICH 22] \\
\hline $\begin{array}{l}\text { Financial } \\
\text { implications }\end{array}$ & 0 & 1 & $\begin{array}{l}\text { "Unfortunately the downside is that it affects new admissions which } \\
\text { then affects income" [ICH 36] }\end{array}$ \\
\hline Total & 12 & 32 & \\
\hline
\end{tabular}

\section{Discussion}

We found that TSV practice varied considerably across the NHS in Scotland, with inconsistent availability and use of criteria or policy to guide clinical staff in making decisions 
about implementing TSV. In some areas there was a clear policy in place and TSV was routinely implemented; in others there was a policy not to use TSV at all and to advise visitors of the risks instead, reportedly due to concern regarding patient and public involvement partners' views. The inconsistent availability and use of policy-based criteria raises questions around the factors that may influence NHS Boards to establish TSV policy (or not) and whether this is an active or passive process i.e. why do some boards have TSV policies whilst others do not? Some NHS respondents indicated their Boards have actively determined that they do not agree with TSV and therefore will not establish criteria i.e. it is their policy not to implement TSV, however for some it may be a more passive process whereby in the absence of criteria, no TSV decision is made. In the ICH, TSV practice was more consistent, with the majority of care homes having a clear policy based on national guidance $^{8}$ and implementing TSV for all suspected norovirus outbreaks. Similarly, there was broad agreement across both the $\mathrm{NHS}$ and $\mathrm{ICH}$ sector that exceptions were made when the patient / resident was ill or palliative care was required; views were more mixed in relation to allowing exceptions when the visitor was insistent or had travelled a long distance.

Respondent comments in the survey suggested a perceived lack of clarity around the evidence base for the benefits of suspending visiting, with some variation in perceptions of the rationale for TSV in relation to the role of visitors in the spread of infection; comments suggest the visitor can be perceived as a risk for bringing the virus in from the community, spreading the virus within the care environment, or taking the virus back out into the community, becoming affected themselves in the process. Whilst all of these are possibilities, this variation in perception of the role of visitors may affect beliefs regarding the effectiveness of TSV as an outbreak intervention. Whilst limited, there is some evidence that norovirus can be brought into care environments by visitors, ${ }^{9,}{ }^{10}$ however not all respondents seemed aware of these findings.

Whilst suspending the entry of visitors to areas affected by norovirus could be viewed as a simple outbreak control measure, review of international infection control guidance indicates that this is not necessarily commonplace and that evidence to underpin the measure is limited. Early 2000 UK guidance on norovirus did not advocate visitor restrictions; ${ }^{1}$ there is advice to exclude non-essential personnel, but the specific recommendation re visitors is: "Caution visitors and emphasize hand hygiene". This was stated to be a Category II recommendation i.e. "strongly recommended and viewed as effective by experts in the field and by the working group, based on strong rationale and suggestive evidence, even though definitive studies may not have been done"1. Updated UK professional guidance defined closure as being wider than closure to new admissions, non-essential staff and transfers of patients. ${ }^{6}$ This guidance recommends "All non-essential personnel should be prohibited from 
entering the closed area. This includes non-essential social visitors of patients." The evidence for this recommendation is graded 1D, i.e. "Strongly recommended and supported by expert opinion and wide acceptance as good practice, with no study evidence". The lack of study evidence refers to the measure itself and not the broader impact of the measure for which there is also no study evidence.

The American Centres for Disease Control and Prevention (CDC) introduced a restriction on non-essential visitors in their 2011 guidance. ${ }^{11}$ This was the first healthcare setting guidance produced by the CDC. The recommendation to establish visitor policies for acute gastroenteritis and to restrict non-essential visitors from affected areas during outbreaks is categorised as a 1B recommendation, i.e. 'a strong recommendation based on weak evidence.' In New Zealand, visitor restrictions are advocated thus; 'minimise visits to symptomatic cases.' and 'prevent visitors of a suspect case from visiting other patients or residents. ${ }^{12}$ This guidance does not assess the evidence supporting the recommendation.

In contrast to the findings of our study, some outbreak reports have included a restriction for 'visitors of affected patients', but not a care setting wide restriction. ${ }^{13,14}$ In a review of documented outbreaks of nosocomial norovirus to identify recommended control measures a comprehensive search identified 41 relevant papers (2000-10). ${ }^{15}$ In these 41 papers, a total of 302 control measures were listed of which only $5(1.7 \%)$ were to prohibit visitors. Therefore, it is perhaps unsurprising that our survey of practice within one country parallels the inconsistencies in advice offered in the international literature.

In general, the majority of respondents think that TSV has a helpful role in managing norovirus outbreaks; however a range of perspectives were offered by individuals, from TSV was 'nothing new' and routinely practised to others commenting that it was not a standard strategy, whilst another acknowledged the need for national policy. It is perhaps notable that only NHS respondents questioned the place of TSV in relation to patients' rights to have visitors or highlighted uncertainty over the strength of the evidence base for the effectiveness of TSV.

The findings from our study serve to highlight inconsistencies in the application of national guidance on the restriction of visitors during norovirus outbreaks, with variable translation of guidance into local policies with criteria for implementing TSV. Although limited by the selfreporting nature of the survey, the data presented here describe the practice reported by Infection Prevention \& Control Leads from every NHS Board in Scotland and therefore may be considered representative of the national picture. Whilst the response rate of $27 \%$ of the Scottish Care membership from the ICH sector cannot be said to make the results 
generalizable, the relative consistency in $\mathrm{ICH}$ responses does suggest that our findings are likely to represent typical $\mathrm{ICH}$ practice.

\section{Conclusions:}

Recent international guidelines for the management of norovirus outbreaks recommend restricted visiting as a control measure, although the temporary restriction of visiting is perhaps less explicit; however it is acknowledged that the evidence base for the role of visitors in transmission of norovirus is limited and further research is required.

Our results indicate that, whilst TSV is more commonly applied within the Independent Care Home sector, there is evidence of inconsistent practice in relation to the availability and use of criteria to guide decision making regarding TSV in the NHS. Concerns regarding patients' rights appear to influence the decision to avoid TSV in some NHS Boards, indicating the need for further research into the public acceptability of this measure.

Overall, our findings would support a recommendation for review of available national guidance around norovirus outbreak management, with the goal of determining specific and explicit policy related to the use of TSV. IPC Leads should then consider the translation of national guidance into clear local policy to improve consistency in the use of TSV in practice.

\section{References:}

1. Chadwick PR, Beards G, Brown D, et al. Management of hospital outbreaks of gastroenteritis due to small round structured viruses. J Hosp Infect 2000;45:1-10.

2. Said MA, Perl TM, Sears CL. Healthcare epidemiology: gastrointestinal flu: norovirus in health care and long-term care facilities. Clin Infect Dis 2008;47:1202-1208.

3. Loveridge $\mathrm{P}$, Cooper D, Elliot AJ, et al. Vomiting calls to NHS Direct provide an early warning of norovirus outbreaks in hospitals. J Hosp Infect 2010;74:385-393.

4. Danial J, Cepeda JA, Cameron F, Cloy K, Wishart D, Templeton KE. Epidemiology and costs associated with norovirus outbreaks in NHS Lothian, Scotland 2007-2009. J Hosp Infect 2011;79:354-358.

5. Harris JP, Edmunds WJ, Pebody R, Brown DW, Lopman BA. Deaths from norovirus among the elderly, England and Wales. Emerg Infect Dis 2008;14:1546-52.

6. Health Protection Agency, British Infection Association, Healthcare Infection Society, Infection Prevention Society, National Concern for Healthcare Infections, NHS Confederation. Guidelines for the management of norovirus outbreaks in acute and community health and social care settings. Health Protection Agency . 2012. 15-2-2012.

7. Elo S, Kyngas H. The qualitative content analysis process. J Adv Nurs 2008;62:107-115.

8. Health Protection Scotland. General information and infection prevention and control precautions to prepare for and manage norovirus in care homes. 
http://www.hps.scot.nhs.uk/giz/guidelinedetail.aspx?id=60453\&subjectid=125. Health Protection Scotland . 2014. 1-9-2015.

9. Petrignani $\mathrm{M}$, van $\mathrm{BJ}$, Borsboom $\mathrm{G}$, Richardus $\mathrm{JH}$, Koopmans $\mathrm{M}$. Norovirus introduction routes into nursing homes and risk factors for spread: a systematic review and metaanalysis of observational studies. J Hosp Infect 2015;89:163-178.

10. Xerry J, Gallimore Cl, Cubitt D, Gray JJ. Tracking environmental norovirus contamination in a pediatric primary immunodeficiency unit. $J$ Clin Microbiol 2010;48:2552-2556.

11. Centres for Disease Control and Prevention. Guideline for the prevention and control of norovirus gastroenteritis outbreaks in healthcare settings.

http://www.cdc.gov/hicpac/pdf/norovirus/Norovirus-Guideline-2011.pdf. Centres for Disease Control and Prevention . 2011. 6-2-2015.

12. New Zealand Ministry of Health. Guidelines for the Management of Norovirus Outbreaks in Hospitals and Elderly Care Institutions.

http://www.health.govt.nz/publication/guidelines-management-norovirus-outbreakshospitals-and-elderly-care-institutions-0. New Zealand Ministry of Health . 2009. 1-92015.

13. Georgiadou S, Loukeris D, Smilakou S, Daikos G, Sipsas N. Effective control of an acute gastroenteritis outbreak due to norovirus infection in a hospital ward in Athens, Greece, April 2011. Euro Surveill 2011;16.

14. Greig JD, Lee MB. A review of nosocomial norovirus outbreaks: infection control interventions found effective. Epidemiol Infect 2012;1-10. 